\title{
Fridun Kerschbaumer, Kuno Weise, Carl J. Wirth, Alaxander R. Vaccaro: Operative approaches in orthopedic surgery and traumatology
}

\author{
Thieme Verlag, New York, Stuttgart, Delhi, Rio de Janeiro, June 2015, 412 pp, 747 \\ illustr., Hardback: EUR 222.15, Format Kindle: EUR 160,20, ISBN: 978-3-13-7055020
}

Pierre Kehr ${ }^{1}$

Received: 15 March 2016/Accepted: 25 April 2016/Published online: 10 June 2016

(C) Springer-Verlag France 2016

It is the second edition of this famous book on the ways initially in orthopedic surgery. 27 years after the first edition, this book of author was transformed into a book multiauteurs taking of account the surgical novel methods protecting soft fabrics (arthroscopic and minis invasive).

More than 700 illustrations, the participation of anatomists of the University of Tübingen, 17 different authors make of it a book easy to read and very practical use.

It is divided into four parts: the former access then posterior of the spine, the pelvis and the lower extremity, the shoulder and the upper limb.

In each chapter, the text is precise and concise, the many and clear illustrations with splendid drawings colors of each stage of the surgical access.
The initially described ways are traditional, and one will be able to regret the absence of description of technical alternatives in certain indications. On the other hand, the description of the anatomical alternatives is extremely useful.

This book could be regularly consulted to learn or remind a particular technique.

Compliance with ethical standards

Conflict of interest None.

Pierre Kehr

pierre.kehr@gmail.com

1 Strasbourg, France 